\title{
Evidence-Based Medicine of Screening of Diabetic Retinopathy among Type 2 Diabetes: A Clinical Overview
}

\author{
Yeu-Tyng Lin ${ }^{*}$, Yen-Chen Chen ${ }^{2 *}$, Yu-Ting Peng ${ }^{3}$, Lujie Chen ${ }^{3}$, Jorn-Hon Liu², Fu-Li Chen ${ }^{3}$, \\ Tao-Hsin Tung3,4\# \\ ${ }^{1}$ Department of Family and Community Medicine, Cheng-Hsin General Hospital, Taipei, Taiwan \\ ${ }^{2}$ Department of Ophthalmology, Cheng-Hsin General Hospital, Taipei, Taiwan \\ ${ }^{3}$ Faculty of Public Health, College of Medicine, Fu-Jen Catholic University, Taipei, Taiwan \\ ${ }^{4}$ Department of Medical Research and Education, Cheng-Hsin General Hospital, Taipei, Taiwan \\ Email: ${ }^{*}$ ch2876@chgh.org.tw
}

Received 20 May 2015; accepted 25 July 2015; published 28 July 2015

Copyright (C) 2015 by authors and Scientific Research Publishing Inc.

This work is licensed under the Creative Commons Attribution International License (CC BY).

http://creativecommons.org/licenses/by/4.0/

c) (i) Open Access

\begin{abstract}
Diabetic retinopathy (DR) is a well-characterized chronic ocular disorder that developed in nearly all diabetic patients in the long run. The knowledge of DR is crucial to manage this disorder when planning screening and preventive programs and identifying the appropriated therapeutic strategies among. Expectant management may represent a valid therapeutic approach depending upon the clinical manifestations of the disease and, in particular, on the changes over time. If early treatment of DR reduces the probability of severe stage or slows the progression of blindness, it might sufficiently reduce treatment costs in later years to offset the costs of screening and early treatment. In addition, whether screening for DR is worthwhile is contingent on whether subjects are willing to pay the eye screening program that would decrease the risk of photocoagulation. In this review we discuss epidemiology, management, and economic evaluation of screening of DR among type 2 diabetes.
\end{abstract}

\section{Keywords}

Diabetic Retinopathy, Epidemiology, Economic Evaluation, Screening, Type 2 Diabetes

\section{Introduction}

It was estimated that 366 million people globally had diabetes in 2011, however, more than half of whom were

\footnotetext{
*Yeu-Tyng Lin and Yen-Chen Chen contributed equally in this study.
}

${ }^{\#}$ Corresponding author.

How to cite this paper: Lin, Y.-T., Chen, Y.-C., Peng, Y.-T., Chen, L.J., Liu, J.-H., Chen, F.-L. and Tung, T.-H. (2015) Evidence-Based Medicine of Screening of Diabetic Retinopathy among Type 2 Diabetes: A Clinical Overview. Health, 7, 873883. http://dx.doi.org/10.4236/health.2015.77103 
undiagnosed [1]. Type 2 diabetes may present with clear and classical symptoms including thirst, polyuria, or ketoacidosis and may be accompanied by specific micro- or macro-complications. Most patients were asymptomatic in the early stage and were difficult to diagnose [2]. Many developing countries already have high prevalence of type 2 diabetes and related complications, which typically form the greatest social and health care costs of diabetes. In Taiwan, the remarkable economic achievements of the last 40 years have resulted in a great improvement in living standards and in an increase in life expectancy. Type 2 diabetes in adults is one of the global public health problems in the Taiwanese population. Screening for type 2 diabetes by the natural history of diabetes, fasting plasma glucose (FPG), and oral glucose tolerance test (OGTT) revealed the overall prevalence of type 2 diabetes in Taiwan to be 5\% - 9\% and 11\% - 13\% for residents above 20 or 40 years of age, respectively [3]-[9].

Microvascular and macrovascular diseases are the major causes of morbidity and mortality among type 2 diabetes. Diabetic retinopathy (DR), a complication involving the retinal microvasculature resulting in damage to the retina from ischema, neovascularization, hemorrhage, and edema-is one of the leading causes of visual impairment in type 2 diabetes in Taiwan today [10] [11]. Visual loss from DR is largely preventable with early screening and the timely application of photocoagulation therapy [10]. Based on the Wilson criteria, DR is matched for screening due to it is an essential health problem; the disease natural history should be understood; a recognizable latent or early symptomatic stage; a diagnostic test is easy to perform and interpret, acceptable, accurate, reliable, good sensitivity and specificity; an acceptable treatment regime for the disease; early treatment is more effective; a policy on what kinds of patients should be treated; diagnosis and treatment are costeffective; and case finding should be a continuous process [12]. From the viewpoint of preventive medicine, early detection of this disorder by regular screening followed by appropriate treatment could prevent the resulting blindness. This clinical review aims to explore epidemiology, management, and economic evaluation of screening of DR among type 2 diabetes.

\section{The Clinical Diagnosis of Diabetic Retinopathy}

DR is a microangiopathy of the retina. The typical histopathological changes include loss of pericytes and endothelial cells and thickening and basement membrane thickening [13]. The pathogenesis of DR is multifactorial but is primarily caused by the metabolic effects of chronic exposure to hyperglycaemia [14]. Other mechanisms including the action of insulin-like growth factor 1 (IGF-1) [15]; up-regulation of vascular endothelial growth factor (VEGF) and renin-angiotensin [14] [16]; increased activation of retinal cellular protein-kinase C [17] [18], inflammatory mediators [19] [20], production of reactive-oxygen species [21] [22], carbonic anhydrase [23], growth hormone and advanced glycation end-products (AGE) [24]; increased platelet adhesiveness and erythrocyte aggregation; abnormal serum lipids, abnormalities in serum and whole blood viscosity.

For the investigation, evaluating the patients will include: (A) Complete history and clinical ocular examination including fundus biomicroscopy; (B) Stereoscopic color fundus photography; (C) Fluorescein angiography will help to determine the origin of the leakage from retinal neovascularisation and identify the ischemic areas; (D) Optical coherence tomography (OCT) functions as an optical biopsy of the retina, offering three-dimensional or cross-sectional images; (E) A comprehensive and systemic examination for patients with newly diagnosed diabetic retinopathy. Based on the Diabetic Retinopathy Disease Severity Scale [25] [26], DR was classified as follows: no diabetic retinopathy (NDR, no abnormalities), mild non-proliferative diabetic retinopathy (mild NPDR, only subjects with microaneurysms), moderate non-proliferative diabetic retinopathy (moderate NPDR, subjects with more than just microaneuysms but less than severe NPDR), severe non-proliferative diabetic retinopathy (severe NPDR, subjects with any of the following: more than 20 intraretinal hemorrhages in each of 4 quadrants; definite venous beading in 2+ quadrants; prominent intraretinal microvascular abnormalities in 1+ quadrant; and no signs of proliferative diabetic retinopathy), and proliferative diabetic retinopathy (PDR, subjects with one or more of the following: neovascularization, vitreous/preretinal hemorrhage). In addition, clinically significant macular edema (CSME) is classified as thickening of the retina $\leq 500 \mu \mathrm{m}$ from the center of the macula or hard exudates and adjacent retinal thickening $\leq 500 \mu \mathrm{m}$ from macular center or zone of retinal thickening at least 1 disc area in size located $\leq 1$ disc diameter from the center of the macula [27].

\section{The Epidemiology of Diabetic Retinopathy}

The study of the epidemiology of DR has been greatly improved by the development and adoption of a standar- 
dized grading scheme. Good-quality epidemiological information are imperative to support the planning and implementation of public health or prevention medicine policies and programs and to determine research priorities [1]. Many evidence-based studies of the prevalence, incidence, and risk factors for DR have been conducted. However, it is difficult to appropriately compare the results of some studies because the heterogeneous nature of studies (for example, the study patients' selection and the type of diabetes) and the disparate screening methodologies (for example, the selection of eight-field color fundus photography versus two-field color fundus photography and ophthalmoscopy versus slit-lamp examination), which varied significantly. Although rates of DR vary by time and geographic location, nearly everyone with diabetes will develop DR within 20 years of diagnosis [28]. The microaneurysm is the hallmark of retinal microvascular change in NPDR [10]. Mild non-proliferative changes will usually be present for many years before vision is affected. Upon international comparison, the prevalence of any type of DR and PDR were 3.6\% - 85\% and 0\% - 66\%, respectively [29]-[69]. Although there being many results showing disparity of diabetes prevalence between ethnic groups [70]-[72], relatively few studies have investigated ethnic differences in DR [69]. The multi-ethnic populations indicated that the prevalence of DR differs by ethnic group [69]. Further studies are needed to explore whether ethnicity is an independent risk factor for DR or it is likely that differential susceptibility to risk factors, late diagnosis of diabetes and differential access and use of healthcare contribute to the differences seen in the context of DR diagnosis such a health screening.

To investigate the incidence and risk factors of DR among type 2 diabetes is essential to prevent its development and the visual impairment caused by this complication which is often insidious in nature. In comparison with prevalence studies, there are far fewer studies of the incidence of DR. It is difficult to compare the results across study populations due to the different grading systems used. As seen in the prevalence results, the incidence of DR or PDR is related to the duration of type 2 diabetes [73]-[75]. Consistent temporal trends are not obvious because of the variation in screening methodology and the reporting of results [76]-[82]. The population-based screening showed the 3-year 18.2\% cumulative incidence was (95\% CI: $14.8 \%-21.5 \%)$ and incidence density was 6.62\% per year (95\% CI:5.36\% - 8.06\% per year) in Kinmen, Taiwan [83]. In Beijing eye study, incidence of DR was estimated $4.2 \%$ (95\% CI: 3.45\% - 5.03\%) in the 10-year period [77]. It is necessary to develop a chronic complication model that incorporates the known epidemiology of this diabetes-related disease and allows the effects of intervention to be modeled in order to understand the progression and natural history of DR and to ultimately determine the effect of preventive strategies.

\section{The Natural Course of Diabetic Retinopathy}

Eye screening strategies of DR depend on the rates of appearance and progression and on risk factors that alter these rates. The natural history of DR has been evaluated in four well-organized national multi-center clinical trials: the Diabetic Retinopathy Study (DRS) [84], the Early Treatment Diabetic Retinopathy Study (ETDRS) [85], the Diabetic Retinopathy Vitrectomy Study (DRVS) [86], and the Diabetes Control and Complications Trial (DCCT) [87]. Previously, the modified natural history of DR could be identified as follows: No DR $\rightarrow$ $\mathrm{BDR} \rightarrow \mathrm{PPDR} \rightarrow \mathrm{PDR} \rightarrow$ Blindness (No DR: no diabetic retinopathy, BDR: background diabetic retinopathy, PPDR: preproliferative diabetic retinopathy, PDR: proliferative diabetic retinopathy). The average times spent by using multi-state Markov models in the states No DR, BDR, PPDR, and PDR were 10.86 years, 8.33 years, 1.67 years, and 2.17 years, respectively [88]. Early detection of PPDR could lead to a $60 \%$ reduction in PDR and an $83 \%$ reduction in incident blindness [88]. BDR also could progress to maculopathy and may lead to central visual loss. PDR could result in visual loss due to the proliferation of blood vessels or the detachment of the retina [89] [90]. BDR and PPDR are outdated terms referring to the general levels or stages of NPDR. However, this terminology is not closely associated with disease progression and should no longer be used and has been replaced by the various levels of NPDR, which correlate closely with DR progression [91]. Based on the Diabetic Retinopathy Disease Severity Scale [25] [93], DR was further classified as follows:

No DR $\rightarrow$ mild NPDR $\rightarrow$ moderate NPDR $\rightarrow$ severe NPDR $\rightarrow$ PDR $\rightarrow$ Blindness

By using probabilistic (Monte Carlo) simulation, transition probability of type 2 diabetes with NPDR, PDR, and legal blindness were estimated as $79 \%, 19 \%$, and 19\%, respectively [93]. The population-based in Kinmen indicated that the mean duration in the disease states mild NPDR, moderate NPDR, severe NPDR, and PDR were 4.05 years (95\%: 3.28 - 5.32 years), 4.18 years (95\% CI: 3.18 - 6.06 years), 2.52 years (95\% CI: 1.78 4.27 years), and 4.22 years (95\% CI: 2.88 - 7.81 years), respectively, that means the average time for the devel- 
opment of diabetic retinopathy from nonexistence to blindness was approximately 26.5 years and concluded that annual screening in type 2 diabetes with NPDR should be only for the mild form, but not for the moderate or severe forms [94]. The screening efficacy of preventing blindness associated with DR depends on early detection and further appropriate treatment. The probability of preventing blindness or visual impairment is decreased in the stages of moderate NPDR or PDR among type 2 diabetes. To decide the frequency of fundus check-up, and the sensitivity and specificity of the eye screening tool, it is useful to understand the natural history and progression rate from the asymptomatic to the symptomatic stage and to achieve early detection and treatment efficacy of DR among type 2 diabetes. The timely and appropriate care for type 2 diabetic patients could significantly reduce visual loss over time, not only improving patients' quality of life, but reducing the financial burden associated with the complications of visual impairment [95].

\section{The Economic Evaluation of Screening of Diabetic Retinopathy}

If early treatment of DR reduces the incidence or slows the progression from NPDR, PDR, and then to blindness, it might sufficiently reduce treatment costs in later years to offset the costs of screening and early treatment. Regular examination for DR leads to the early detection of asymptomatic vision-threatening DR among type 2 diabetes. Although direct ophthalmoscopy through dilated pupils only has a sensitivity of approximately $60 \%$, regular repeat screening could compensate for the relatively low sensitivity to remain an efficient and highly cost-effective screening approach [96]. Indirect ophthalmoscopy performed by ophthalmologists has a sensitivity of approximately $85 \%$ [97], this may approach $100 \%$ with newer slit lamp biomicroscopic techniques [28]. The retinal photography has an overall sensitivity of approximately $85 \%$ imply that this approach is also an alternative detection method for DR among diabetic patients [98]. In addition, non-mydriatic retinal cameras may be operated by personnel with minimal training and the photographs forwarded to a reading center. Since a sensitivity greater than $80 \%$ in the detection of PDR were achieved by general practitioners, optometrists, diabetologists, and an independent grader using retinal photography, there is no clear evidence to show in whose hands this method works best [99]. However, the main limitation of indirect ophthalmoscopy is the proportion of unreadable photographs, particularly in elderly diabetic patients due to small pupils and media opacity such as cataract [100].

It is essential to ensure that appropriate and effective implementation methods are commissioned to support the decision-making process of DR. Retinal digital photography, that is, telemedicine has emerged as a lower cost alternative to annual evaluation by an eye-care professional [11]. Telemedicine uses digital retinal photography to enable eye screening in nonophthalmologic settings. Images are electronically transferred to a grading center for clinical evaluation, and patients with evidence of mild to severe DR are then referred to an eye-care institute for a further evaluation. Telemedicine showed better sensitivity (98\%) and specificity (86\%) for DR detection than ophthalmoscopy and usually less costly from both the health care and societal perspectives than dilated eye examinations due to lower provider reimbursements and lower patient productivity losses from time lost to treatment [11] [101]. To compare the efficacy of different screening methods for DR among type 2 diabetes, mydriatic retinal photography provides the most sensitivity screening and monitoring test for detection of DR among type 2 diabetes based on an assessment of available follow-up studies [102]. Ophthalmoscopy as a screening or monitoring method for DR still has a place in routine clinical practice as well as having a limited place in screening programs. Where photographs are ungradable, then ophthalmoscopy should be used as an adjunctive method [102].

Whether screening for DR is worthwhile is also contingent on whether diabetic patients are willing to pay the eye screening program that would decrease the risk of blindness or visual impairment. Economic evaluation, such as cost-effectiveness analysis (CEA), cost-utility analysis (CUA), and cost-benefit analysis (CBA) methods, explores the efficacy of DR prevention among type 2 diabetes. Many evidence-based studies have supported that screening for and treating DR is extremely cost-effective. For type 2 diabetes, over 10 years, 67 versus 56 sight years were saved, compared with no screening, at a cost of USD 3900 versus USD 9800 per sight year and USD 15,000 versus USD 37,000 per quality-adjusted life-year (QALY) [99]. In the US population, retinal screening annually versus every other year for type 2 diabetes cost USD 107,510 per QALY gained, while screening every other year versus every third year costs USD 49,760 per QALY gained and concluded that annual retinal screening for all type 2 diabetics without previously detected DR may not be warranted on the basis of cost-effectiveness [103]. From the health insurer's perspective, screening and treatment of eye disease in type 2 
diabetes costs USD 3190 per QALY saved [104]. Polak et al. showed that an additional one year sight gain may cost 1126 Euros by providing ophthalmological care and 50,479 Euros by glycemic control. The duration of blindness drops in type 2 diabetics by 0.48 and 0.13 years, respectively, whereas the effectiveness decreases as the age of onset of diabetes rises [105]. The prevention programs aimed at improving eye care for diabetic patients not only result insubstantial federal budgetary savings, but are also highly cost-effective health investments for society [104]. Using the CBA approach, Matz et al. showed that the anticipated annual costs for blindness were ATS 19,000,000, of which ATS 14,600,000 could be avoided through optimal screening, examination, and therapy programs [106]. In Taiwan, due to different ethics and medical environment than other countries, it is essential to organize an effective screening program and consider costs and benefits carefully before setting universal standards. Annual screening for DR among Chinese with type 2 diabetes should be conducted. Prevention programs aimed at improving eye care for patients with type 2 diabetes results in both substantial federal budgetary savings and highly cost-effective health care [96]. It is worthwhile to initial a routine DR screening of Chinese type 2 diabetes for blindness prevention from the societal perspective but not from consumer decision based on the willingness-to-pay perspective [107].

\section{The Management of Diabetic Retinopathy}

International multicenter studies have showed the efficacy and effectiveness of clinical treatments of diabetes with DR [84] [85] [108] [109]. To maintain strict blood glucose levels and blood pressure have proven very difficult for most parts of diabetic patients and the risk of hypoglycemia is increased under this treatment regimen although clinical evidences suggesting that intensive glycemic therapy is more effective in controlling diabetic complications [110]. Further, laser photocoagulation treatment and vitrectomy are both two major clinical therapies for preventing the deterioration of severe stage of DR. It has been estimated that without appropriate treatment for PDR, 50\% of diabetic patients will become blindness within 5 years following diagnosis [95]. The impact of timely laser treatment in diabetic patients with PDR is dramatic. Eyes affected by DR and received photocoagulation therapy were found to have better average visual acuity and a lower rate of blindness than control eyes at perspective study [111]. Scatter photocoagulation could reduce the risk of blindness by $60 \%$ in DRS-treated eyes with high-risk PDR [112]. Furthermore, only 4\% of eyes with PDR treated with panretinal photocoagulation in the ETDRS had reached severe visual loss by 5 years and only $1 \%$ of diabetic patients had this degree of visual loss in both eyes [25]. The ETDRS also revealed that focal laser treatment of eyes with clinically significant macular edema (areas of retinal thickening around the macula) reduced the risk of moderate visual loss by 50\% or more [85]. General speaking, all evidences implied that to be most effective, laser treatment must be applied before significant visual impairment occurs.

\section{Conclusion}

In conclusion, DR is an escalating major health problem and includes constitutional and environmental factors. The challenge of DR is clearly no longer solely a biomedical one. It must also be solved through effective delivery of health services, more motivated and empowered consumers, and proactive providers. Before carrying out the screening and achieving the object of prevention for DR, it is also essential to understand the epidemiologic information of DR. Screening for DR is both medically and economically worthwhile. In the absence of a suitable screening program for symptomatic DR, treating DR and related complications yields substantial healthcare costs. Annual screening in type 2 diabetes with NPDR should be only for the mild form, but not for the moderate or severe forms. It should be able to assess effectively the natural history of DR and economic evaluation of screening if the lone-term follow-up study of DR for type 2 diabetes is based on community design to utilize the information of scheduled screening of diabetes with DR for analysis.

\section{Competing Interests}

The authors declare that they have no competing interests.

\section{Author Contributions}

Yen-Chen Chen, Jorn-Hon Liu, and Tao-Hsin Tung drafted the manuscript. Yeu-Tyng Lin, Yu-Ting Peng, Lujie Chen, and Fu-Li Chen coordinated drafting the manuscript. All authors read and approved the final version of 
the manuscript.

\section{References}

[1] Ruta, L.M., Magliano, D.J., LeMesurier, R., Taylor, H.R., Zimmet, P.Z. and Shaw, J.E. (2013) Prevalence of Diabetic Retinopathy in Type 2 Diabetes in Developing and Developed Countries. Diabetic Medicine, 30, 387-398. http://dx.doi.org/10.1111/dme.12119

[2] Szabo, S.M., Beusterien, K.M., Pleil, A.M., et al. (2010) Patient Preferences for Diabetic Retinopathy Health States. Investigative Ophthalmology \& Visual Science, 51, 3387-3394. http://dx.doi.org/10.1167/iovs.09-4194

[3] Lin, J.D., Shieh, W.B., Huang, M.J. and Huang, H.-S. (1993) Diabetes Mellitus and Hypertension Based on the Family History and 2-h Postprandial Blood Sugar in the Ann-Lo District (Northern Taiwan). Diabetes Research and Clinical Practice, 20, 75-85. http://dx.doi.org/10.1016/0168-8227(93)90026-2

[4] Li, C.L., Tsai, S.T. and Chou, P. (1999) Comparison of the Results between Two Diagnostic Criteria by ADA and WHO among Subjects with FPG 5.6-7.8 mmol/l in Kin-Hu and Kin-Chen, Kinmen, 1991-94. Diabetes Research and Clinical Practice, 45, 51-59. http://dx.doi.org/10.1016/S0168-8227(99)00050-9

[5] Chou, P., Liao, M.J., Kuo, H.S., Hsiao, K.J. and Tsai, S.T. (1994) A Population Survey on the Prevalence of Diabetes in Kin-Hu, Kinmen. Diabetes Care, 17, 1055-1058. http://dx.doi.org/10.2337/diacare.17.9.1055

[6] Chou, P., Li, C.L., Kuo, H.S., Hsiao, K.J. and Tsai, S.T. (1997) Comparison of the Prevalence of Two Diabetes Surveys in Pu-Li, Taiwan, 1987-1988 and 1991-1992. Diabetes Research and Clinical Practice, 38, 61-67. http://dx.doi.org/10.1016/S0168-8227(97)00091-0

[7] Chen, H.D., Shaw, C.K., Tseng, W.P., Chen, H.I. and Lee, M.L. (1997) Prevalence of Diabetes Mellitus and Impaired Glucose Tolerance in Aborigines and Chinese in Eastern Taiwan. Diabetes Research and Clinical Practice, 38, 199205. http://dx.doi.org/10.1016/S0168-8227(97)00104-6

[8] Lu, F.H., Yang, Y.C., Wu, J.S., Wu, C.H. and Chang, C.J. (1998) A Population-Based Study of the Prevalence and Associated Factors of Diabetes Mellitus in Southern Taiwan. Diabetic Medicine, 15, 564-572. http://dx.doi.org/10.1002/(SICI)1096-9136(199807)15:7<564::AID-DIA615>3.0.CO;2-H

[9] Chen, K.T., Chen, C.J., Gregg, E.W., Williamson, D.F. and Narayan, K.M.V. (1999) High Prevalence of Impaired Fasting Glucose and Type 2 Diabetes Mellitus in Penghu Islets, Taiwan: Evidence of a Rapidly Emerging Epidemic? Diabetes Research and Clinical Practice, 44, 59-69. http://dx.doi.org/10.1016/S0168-8227(99)00025-X

[10] Chen, S.J., Chou, P., Lee, A.F., et al. (2010) Microaneurysm Number and Distribution in the Macula of Chinese Type 2 Diabetics with Early Diabetic Retinopathy: A Population-Based Study in Kinmen, Taiwan. Acta Diabetologica, 47, 35-41.

[11] Rein, D.B., Wittenborn, J.S., Zhang, X., et al. (2011) The Cost-Effectiveness of Three Screening Alternatives for People with Diabetes with No or Early Diabetic Retinopathy. Health Services Research, 46, 1534-1561. http://dx.doi.org/10.1111/j.1475-6773.2011.01263.x

[12] Chen, J.Y., Tsai, S.T., Hsu, C.T., et al. (2013) Cost-Benefit Analysis of Screening for Gallstone Disease among Chinese Population in Taiwan. The Open Access Journal of Science and Technology, 1, 1-7. http://dx.doi.org/10.11131/2013/100002

[13] Stitt, A.W., Gardiner, T.A. and Archer, D.B. (1995) Histological and Ultrastructural Investigation of Retinal Microaneurysm Development in Diabetic Patients. The British Journal of Ophthalmology, 79, 362-367.

[14] Frank, R.N. (2004) Diabetic Retinopathy. The New England Journal of Medicine, 350, 48-58. http://dx.doi.org/10.1056/NEJMra021678

[15] Ruberte, J., Ayuso, E., Navarro, M., et al. (2004) Increased Ocular Levels of IGF-1 in Transgenic Mice Lead to Diabetes-Like Eye Disease. The Journal of Clinical Investigation, 113, 1149-1157. http://dx.doi.org/10.1172/JCI19478

[16] Aiello, L.P. (2005) Angiogenic Pathways in Diabetic Retinopathy. The New England Journal of Medicine, 353, 839841. http://dx.doi.org/10.1056/NEJMe058142

[17] Aiello, L.P., Davis, M.D., Girach, A., et al. (2006) Effect of Ruboxistaurin on Visual Loss in Patients with Diabetic Retinopathy. Ophthalmology, 113, 2221-2230. http://dx.doi.org/10.1016/j.ophtha.2006.07.032

[18] PKC-DMES Study Group (2007) Effect of Ruboxistaurin in Patients with Diabetic Macular Edema: Thirty-Month Results of the Randomized PKC-DMES Clinical Trial. Archives of Ophthalmology, 125, 318-324. http://dx.doi.org/10.1001/archopht.125.3.318

[19] Grover, D., Li, T.J. and Chong, C.C. (2008) Intravitreal Steroids for Macular Edema in Diabetes. Cochrane Database of Systematic Reviews, No. 1, Article No. CD005656.

[20] Yilmaz, T., Weaver, C.D, Gallagher, M.J., et al. (2009) Intravitreal Triamcinolone Acetonide Injection for Treatment 
of Refractory Diabetic Macular Edema: A Systematic Review. Ophthalmology, 116, 902-911. http://dx.doi.org/10.1016/j.ophtha.2009.02.002

[21] Nishikawa, T., Edelstein, D., Du, X.L., et al. (2000) Normalizing Mitochondrial Superoxide Production Blocks Three Pathways of Hyperglycaemic Damage. Nature, 404, 787-790. http://dx.doi.org/10.1038/35008121

[22] Lonn, E., Yusuf, S., Hoogwerf, B., et al. (2002) Effects of Vitamin E on Cardiovascular and Microvascular Outcomes in High-Risk Patients with Diabetes: Results of the HOPE Study and MICRO-HOPE Substudy. Diabetes Care, 25, 1919-1927. http://dx.doi.org/10.2337/diacare.25.11.1919

[23] Gao, B.B., Clermont, A., Rook, S., et al. (2007) Extracellular Carbonic Anhydrase Mediates Hemorrhagic Retinal and Cerebral Vascular Permeability through Prekallikrein Activation. Nature Medicine, 13, 181-188. http://dx.doi.org/10.1038/nm1534

[24] Bolton, W.K., Cattran, D.C., Williams, M.E., et al. (2004) Randomized Trial of an Inhibitor of Formation of Advanced Glycation end Products in Diabetic Nephropathy. American Journal of Nephrology, 24, 32-40. http://dx.doi.org/10.1159/000075627

[25] Early Treatment Diabetic Retinopathy Study Research Group (1991) Early Photocoagulation for Diabetic Retinopathy: ETDRS Report Number 9. Ophthalmology, 98, 766-785. http://dx.doi.org/10.1016/S0161-6420(13)38011-7

[26] Wilkinson, C.P., Ferris, F.L., Klein, R.E., Lee, P.P., Agardh, C.D., Davis, M., et al. (2003) Proposed International Clinical Diabetic Retinopathy and Diabetic Macular Edema Disease Severity Scales. Ophthalmology, 110, 1677-1682. http://dx.doi.org/10.1016/S0161-6420(03)00475-5

[27] Aiello, L.M. (2003) Perspectives on Diabetic Retinopathy. American Journal of Ophthalmology, 136, 122-135. http://dx.doi.org/10.1016/S0002-9394(03)00219-8

[28] Ekoe, J.M., Zimmet, P. and Williams, R. (2001) The Epidemiology of Diabetes Mellitus: An International Perspective. John Wiley \& Sons, Inc., Hoboken.

[29] Al-Rubeaan, K., Abu El-Asrar, A.M., Youssef, A.M., et al. (2014) Diabetic Retinopathy and Its Risk Factors in a Society with a Type 2 Diabetes Epidemic: A Saudi National Diabetes Registry-Based Study. Acta Ophthalmologica, 93, e140-e147.

[30] Li, L., Ji, L., Guo, X., et al. (2014) Prevalence of Microvascular Diseases among Tertiary Care Chinese with Early versus Late Onset of Type 2 Diabetes. Journal of Diabetes and its Complications, 29, 32-37.

[31] Costanian, C., Bennett, K., Hwalla, N., et al. (2014) Prevalence, Correlates and Management of Type 2 Diabetes Mellitus in Lebanon: Findings from a National Population-Based Study. Diabetes Research and Clinical Practice, 105, 408-415. http://dx.doi.org/10.1016/j.diabres.2014.06.005

[32] Collier, A., Ghosh, S., Hair, M., et al. (2014) Gender Differences and Patterns of Cardiovascular Risk Factors in Type 1 and Type 2 Diabetes: A Population-Based Analysis from a Scottish Region. Diabetic Medicine, 23, 42-46.

[33] Thomas, R.L., Dunstan, F.D., Luzio, S.D., et al. (2014) Prevalence of Diabetic Retinopathy within a National Diabetic Retinopathy Screening Service. British Journal of Ophthalmology, 99, 64-68.

[34] Cander, S., Coban, S., Altuner, S., et al. (2014) Prevalence and Correlates of Erectile Dysfunction in Type 2 Diabetes Mellitus: A Cross-Sectional Single-Center Study among Turkish Patients. Metabolic Syndrome and Related Disorders, 12, 324-329. http://dx.doi.org/10.1089/met.2013.0150

[35] Sosale, A., Prasanna Kumar, K.M., Sadikot, S.M., et al. (2014) Chronic Complications in Newly Diagnosed Patients with Type 2 Diabetes Mellitus in India. Indian Journal of Endocrinology and Metabolism, 18, 355-360. http://dx.doi.org/10.4103/2230-8210.131184

[36] Olafsdottir, E., Andersson, D.K., Dedorsson, I., et al. (2014) The Prevalence of Retinopathy in Subjects with and without Type 2 Diabetes Mellitus. Acta Ophthalmologica, 92, 133-137. http://dx.doi.org/10.1111/aos.12095

[37] Jingi, A.M., Noubiap, J.J., Ellong, A., et al. (2014) Epidemiology and Treatment Outcomes of Diabetic Retinopathy in a Diabetic Population from Cameroon. BMC Ophthalmology, 14, 19. http://dx.doi.org/10.1186/1471-2415-14-19

[38] Sunita, M., Desai, S., Vinay, P., et al. (2014) Aditya Jyot-Diabetic Retinopathy in Urban Mumbai Slums Study (AJDRUMSS): Study Design and Methodology-Report 1. Ophthalmic Epidemiology, 21, 51-60. http://dx.doi.org/10.3109/09286586.2013.867509

[39] Almdal, T.P., Handlos, L.N., Valerius, M., et al. (2014) Glycaemic Threshold for Diabetes-Specific Retinopathy among Individuals from Saudi Arabia, Algeria and Portugal. Diabetes Research and Clinical Practice, 103, e44-e46. http://dx.doi.org/10.1016/j.diabres.2013.12.023

[40] Schellini, S.A., Carvalho, G.M., Rendeiro, F.S., et al. (2014) Prevalence of Diabetes and Diabetic Retinopathy in a Brazilian Population. Ophthalmic Epidemiology, 21, 33-38. http://dx.doi.org/10.3109/09286586.2013.868004

[41] Win Tin, S.T., Kenilorea, G., Gadabu, E., et al. (2014) The Prevalence of Diabetes Complications and Associated Risk Factors in Pacific Islands Countries. Diabetes Research and Clinical Practice, 103, 114-1148. 
http://dx.doi.org/10.1016/j.diabres.2013.09.017

[42] Ghassibe-Sabbagh, M., Deeb, M., Salloum, A.K., et al. (2014) Multivariate Epidemiologic Analysis of Type 2 Diabetes Mellitus Risks in the Lebanese Population. Diabetology \& Metabolic Syndrome, 6, 89. http://dx.doi.org/10.1186/1758-5996-6-89

[43] Rajalakshmi, R., Amutha, A., Ranjani, H., et al. (2014) Prevalence and Risk Factors for Diabetic Retinopathy in Asian Indians with Young Onset Type 1 and Type 2 Diabetes. Journal of Diabetic Complications, 28, 291-297. http://dx.doi.org/10.1016/j.jdiacomp.2013.12.008

[44] Liu, L., Geng, J., Wu, J., et al. (2013) Prevalence of Ocular Fundus Pathology with Type 2 Diabetes in a Chinese Urban Community as Assessed by Telescreening. BMJ Open, 3, e004146. http://dx.doi.org/10.1136/bmjopen-2013-004146

[45] Simić, I., Pećin, I., Tedeschi-Reiner, E., et al. (2013) Risk Factors for Microvascular Atherosclerotic Changes in Patients with Type 2 Diabetes Mellitus. Collegium Antropologicum, 37, 783-787.

[46] Li, N., Yang, X.F., Deng, Y., et al. (2013) Diabetes Self-Management and Its Association with Diabetic Retinopathy in Patients with Type 2 Diabetes. Chinese Journal of Ophthalmology, 49, 500-506.

[47] Ramavat, P.R., Ramavat, M.R., Ghugare, B.W., et al. (2013) Prevalence of Diabetic Retinopathy in Western Indian Type 2 Diabetic Population: A Hospital-Based Cross-Sectional Study. Journal of Clinical and Diagnostic Research, 7, 1387-1390. http://dx.doi.org/10.7860/jcdr/2013/5259.3146

[48] Potisat, S., Krairittichai, U., Jongsareejit, A., et al. (2013) A 4-Year Prospective Study on Long-Term Complications of Type 2 Diabetic Patients: The Thai DMS Diabetes Complications (DD.Comp.) Project. Journal of the Medical Association of Thailand, 96, 637-643.

[49] Tan, E.D., Davis, W.A. and Davis, T.M. (2013) Characteristics and Prognosis of Asian Patients with Type 2 Diabetes from a Multi-Racial Australian Community: The Fremantle Diabetes Study. Internal Medicine Journal, 43, 1125-1132. http://dx.doi.org/10.1111/imj.12246

[50] Islam, S., Harnarayan, P., Cawich, S.O., et al. (2013) Epidemiology of Diabetic Foot Infections in an Eastern Caribbean Population: A Prospective Study. The Permanente Journal, 17, 37-40. http://dx.doi.org/10.7812/TPP/12-126

[51] TODAY Study Group (2013) Retinopathy in Youth with Type 2 Diabetes Participating in the TODAY Clinical Trial. Diabetes Care, 36, 1772-1174. http://dx.doi.org/10.2337/dc12-2387

[52] Mohan, V., Shanthi Rani, C.S., Amutha, A., et al. (2013) Clinical Profile of Long-Term Survivors and Nonsurvivors with Type 2 Diabetes. Diabetes Care, 36, 2190-2197. http://dx.doi.org/10.2337/dc12-1193

[53] McHugh, S., Buckley, C. and Murphy, K. (2013) Quality-Assured Screening for Diabetic Retinopathy Delivered in Primary Care in Ireland: An Observational Study. British Journal of General Practice, 63, e134-e140. http://dx.doi.org/10.3399/bjgp13X663091

[54] Mosenzon, O., Raz, I., Scirica, B.M., et al. (2013) Baseline Characteristics of the Patient Population in the Saxagliptin Assessment of Vascular Outcomes Recorded in Patients with Diabetes Mellitus (SAVOR)-TIMI 53 Trial. Diabetes/ Metabolism Research and Reviews, 29, 417-426. http://dx.doi.org/10.1002/dmrr.2413

[55] Tanaka, S., Tanaka, S., Iimuro, S., et al. (2013) Predicting Macro-and Microvascular Complications in Type 2 Diabetes: The Japan Diabetes Complications Study/the Japanese Elderly Diabetes Intervention Trial Risk Engine. Diabetes Care, 36, 1193-1199. http://dx.doi.org/10.2337/dc12-0958

[56] Bertram, M.Y., Jaswal, A.V. and Van Wyk, V.P. (2013) The Non-Fatal Disease Burden Caused by Type 2 Diabetes in South Africa, 2009. Glob Health Action, 6, 19244. http://dx.doi.org/10.3402/gha.v6i0.19244

[57] Jammal, H., Khader, Y., Alkhatib, S., et al. (2013) Diabetic Retinopathy in Patients with Newly Diagnosed Type 2 Diabetes Mellitus in Jordan: Prevalence and Associated Factors. Journal of Diabetes, 5, 172-179. http://dx.doi.org/10.1111/1753-0407.12015

[58] Kostev, K. and Rathmann, W. (2013) Diabetic Retinopathy at Diagnosis of Type 2 Diabetes in the UK: A Database Analysis. Diabetologia, 56, 109-111. http://dx.doi.org/10.1007/s00125-012-2742-7

[59] Thomas, R.L., Distiller, L., Luzio, S.D., et al. (2013) Ethnic Differences in the Prevalence of Diabetic Retinopathy in Persons with Diabetes When First Presenting at a Diabetes Clinic in South Africa. Diabetes Care, 36, 336-341. http://dx.doi.org/10.2337/dc12-0683

[60] Ai Ghamdi, A.H., Rabiu, M., Hajar, S., et al. (2012) Rapid Assessment of Avoidable Blindness and Diabetic Retinopathy in Taif, Saudi Arabia. British Journal of Ophthalmology, 96, 1168-1172. http://dx.doi.org/10.1136/bjophthalmol-2012-301874

[61] Glover, S.J., Burgess, P.I., Cohen, D.B., et al. (2012) Prevalence of Diabetic Retinopathy, Cataract and Visual Impairment in Patients with Diabetes in Sub-Saharan Africa. British Journal of Ophthalmology, 96, 156-161. http://dx.doi.org/10.1136/bjo.2010.196071 
[62] Gunnlaugsdottir, E., Halldorsdottir, S., Klein, R., et al. (2012) Retinopathy in Old Persons with and without Diabetes Mellitus: The Age, Gene/Environment Susceptibility—Reykjavik Study (AGES-R). Diabetologia, 55, 671-680. http://dx.doi.org/10.1007/s00125-011-2395-y

[63] Polack, S., Yorston, D., López-Ramos, A., et al. (2012) Rapid Assessment of Avoidable Blindness and Diabetic Retinopathy in Chiapas, Mexico. Ophthalmology, 119, 1033-1140. http://dx.doi.org/10.1016/j.ophtha.2011.11.002

[64] Sáles, C.S., Lee, R.Y., Agadzi, A.K., et al. (2012) Prevalence of Diabetes Mellitus and Diabetic Retinopathy in Filipino vs Caucasian Americans: A Retrospective Cross-Sectional Epidemiologic Study of Two Convenience Samples. Ethnicity \& Disease, 22, 459-465.

[65] Elhwuegi, A.S., Darez, A.A., Langa, A.M., et al. (2012) Cross-Sectional Pilot Study about the Health Status of Diabetic Patients in City of Misurata, Libya. African Health Sciences, 12, 81-86.

[66] Doucet, J., Le Floch, J.P., Bauduceau, B., et al. (2012) GERODIAB: Glycaemic Control and 5-Year Morbidity/Mortality of Type 2 Diabetic Patients Aged 70 Years and Older: 1. Description of the Population at Inclusion. Diabetes \& Metabolism, 38, 523-530. http://dx.doi.org/10.1016/j.diabet.2012.07.001

[67] Pugliese, G., Solini, A., Zoppini, G., et al. (2012) High Prevalence of Advanced Retinopathy in Patients with Type 2 Diabetes from the Renal Insufficiency and Cardiovascular Events (RIACE) Italian Multicenter Study. Diabetes Research and Clinical Practice, 98, 329-337. http://dx.doi.org/10.1016/j.diabres.2012.09.006

[68] Zheng, Y., Lamoureux, E.L., Ikram, M.K., et al. (2012) Impact of Migration and Acculturation on Prevalence of Type 2 Diabetes and Related Eye Complications in Indians Living in a Newly Urbanised Society. PLoS ONE, 7, e34829. http://dx.doi.org/10.1371/journal.pone.0034829

[69] Sivaprasad, S., Gupta, B., Gulliford, M.C., et al. (2012) Ethnic Variations in the Prevalence of Diabetic Retinopathy in People with Diabetes Attending Screening in the United Kingdom (DRIVE UK). PLoS ONE, 7, e32182. http://dx.doi.org/10.1371/journal.pone.0032182

[70] Harris, M.I., Eastman, R.C., Cowie, C.C., et al. (1999) Racial and Ethnic Differences in Glycemic Control of Adults with Type 2 Diabetes. Diabetes Care, 22, 403-408. http://dx.doi.org/10.2337/diacare.22.3.403

[71] McBean, A.M., Li, S., Gilbertson, D.T., et al. (2004) Differences in Diabetes Prevalence, Incidence, and Mortality among the Elderly of Four Racial/Ethnic Groups: Whites, Blacks, Hispanics, and Asians. Diabetes Care, 27, 23172324. http://dx.doi.org/10.2337/diacare.27.10.2317

[72] LaVeist, T.A., Thorpe Jr., R.J., Galarraga, J.E., et al. (2009) Environmental and Socio-Economic Factors as Contributors to Racial Disparities in Diabetes Prevalence. Journal of General Internal Medicine, 24, 1144-1148. http://dx.doi.org/10.1007/s11606-009-1085-7

[73] Janghorbani, M., Jones, R.B. and Allison, S.P. (2000) Incidence of and Risk Factors for Proliferative Retinopathy and Its Association with Blindness among Diabetes Clinic Attenders. Ophthalmic Epidemiology, 7, 225-241. http://dx.doi.org/10.1076/opep.7.4.225.4171

[74] Janghorbani, M., Jones, R.B., Murray, K.J., et al. (2001) Incidence of and Risk Factors for Diabetic Retinopathy in Diabetic Clinic Attenders. Ophthalmic Epidemiology, 8, 309-325.

[75] Stratton, I.M., Kohner, E.M., Aldington, S.J., et al. (2001) UKPDS 50: Risk Factors for Incidence and Progression of Retinopathy in Type II Diabetes over 6 Years from Diagnosis. Diabetologia, 44, 156-163. http://dx.doi.org/10.1007/s001250051594

[76] Lin, J.C., Shau, W.Y. and Lai, M.S. (2014) Sex- and Age-Specific Prevalence and Incidence Rates of Sight-Threaten ing Diabetic Retinopathy in Taiwan. JAMA Ophthalmology, 132, 922-928. http://dx.doi.org/10.1001/jamaophthalmol.2014.859

[77] Xu, J., Xu, L., Wang, Y.X., et al. (2014) Ten-Year Cumulative Incidence of Diabetic Retinopathy. The Beijing Eye Study 2001/2011. PLoS ONE, 9, e111320. http://dx.doi.org/10.1371/journal.pone.0111320

[78] Jin, P., Peng, J., Zou, H., et al. (2014) The 5-Year Onset and Regression of Diabetic Retinopathy in Chinese Type 2 Diabetes Patients. PLoS ONE, 9, e113359. http://dx.doi.org/10.1371/journal.pone.0113359

[79] Salinero-Fort, M.Á., San Andrés-Rebollo, F.J. and de Burgos-Lunar, C. (2013) Four-Year Incidence of Diabetic Retinopathy in a Spanish Cohort: The MADIABETES Study. PLoS ONE, 8, e76417. http://dx.doi.org/10.1371/journal.pone.0076417

[80] Ahmed, K.R., Karim, M.N., Bhowmik, B., et al. (2012) Incidence of Diabetic Retinopathy in Bangladesh: A 15-Year Follow-Up Study. Journal of Diabetes, 4, 386-391. http://dx.doi.org/10.1111/j.1753-0407.2012.00208.x

[81] Jones, C.D., Greenwood, R.H., Misra, A., et al. (2012) Incidence and Progression of Diabetic Retinopathy during 17 Years of a Population-Based Screening Program in England. Diabetes Care, 35, 592-596. http://dx.doi.org/10.2337/dc11-0943

[82] Kawasaki, R., Tanaka, S., Tanaka, S., et al. (2011) Incidence and Progression of Diabetic Retinopathy in Japanese 
Adults with Type 2 Diabetes: 8 Year Follow-Up Study of the Japan Diabetes Complications Study (JDCS). Diabetologia, 54, 2288-2294. http://dx.doi.org/10.1007/s00125-011-2199-0

[83] Tung, T.H., Chen, S.J., Liu, J.H., et al. (2005) A Community-Based Follow-Up Study on Diabetic Retinopathy among Type 2 Diabetics in Kinmen. European Journal of Epidemiology, 20, 317-323. http://dx.doi.org/10.1007/s10654-004-6651-z

[84] Diabetic Retinopathy Study Research Group (1981) Design, Methods, and Baseline Results: DRS Report No. 6. Investigative Ophthalmology, 21, 149-209.

[85] Early Treatment Diabetic Retinopathy Study Group (1985) Photocoagulation for Diabetic Macular Edema. ETDRS Report Number 1. Archives of Ophthalmology, 103, 1796-1806.

[86] The Diabetic Retinopathy Vitrectomy Study Research Group (1985) Early Vitrectomy for Severe Vitreous Hemorrhage in Diabetic Retinopathy: Two-Year Results of a Randomized Trial. DRVS Report No. 2. Archives of Ophthalmology, 103, 1644-1652. http://dx.doi.org/10.1001/archopht.1985.01050110038020

[87] The DCCT Research Group (1986) The Diabetes Control and Complications Trial (DCCT): Design and Methodologic Considerations for the Feasibility Phase. Diabetes, 35, 530-545. http://dx.doi.org/10.2337/diab.35.5.530

[88] Liu, W.J., Lee, L.T., Yen, M.F., et al. (2003) Assessing Progression and Efficacy of Treatment for Diabetic Retinopathy Following the Proliferative Pathway to Blindness: Implication for Diabetic Retinopathy Screening in Taiwan. Diabetic Medicine, 20, 727-733. http://dx.doi.org/10.1046/j.1464-5491.2003.01019.x

[89] Foulds, W.S., McCuish, A., Barrie, T., et al. (1983) Diabetic Retinopathy in the West of Scotland: Its Detection and Prevalence, and the Cost-Effectiveness of a Proposed Screening Program. Health Bulletin, 41, 318-326.

[90] Kohner, E.M. (1978) The Evalution and Natural History of Diabetic Retinopathy. International Ophthalmology Clinics, 18, $1-16$

[91] Aiello, L.P., Gardner, T.W., King, G.L., et al. (1998) Diabetes Retinopathy. Diabetes Care, 21, 143-156. http://dx.doi.org/10.2337/diacare.21.1.143

[92] Wilkinson, C.P., Ferris, F.L., Klein, R.E., et al. (2003) Proposed International Clinical Diabetic Retinopathy and Diabetic Macular Edema Disease Severity Scales. Ophthalmology, 110, 1677-1682. http://dx.doi.org/10.1016/S0161-6420(03)00475-5

[93] Eastman, R.C., Javitt, J.C., Herman, W.H., et al. (1997) Model of Complications of NIDDM: I. Model Construction and Assumptions. Diabetes Care, 20, 725-734. http://dx.doi.org/10.2337/diacare.20.5.725

[94] Tung, T.H., Chen, S.J., Shih, H.C., et al. (2006) Assessing the Natural Course of Diabetic Retinopathy: A Population-Based Study in Kinmen, Taiwan. Ophthalmic Epidemiology, 13, 327-333. http://dx.doi.org/10.1080/09286580600826637

[95] Williams, R., Airey, M., Baxter, H., et al. (2004) Epidemiology of Diabetic Retinopathy and Macular Oedema: A Systematic Review. Eye, 18, 963-983. http://dx.doi.org/10.1038/sj.eye.6701476

[96] Tung, T.H., Shih, H.C., Chen, S.J., et al. (2008) Economic Evaluation of Screening for Diabetic Retinopathy among Chinese Type 2 Diabetes: A Community-Based Study in Kinmen, Taiwan. Journal of Epidemiology, 18, 225-233. http://dx.doi.org/10.2188/jea.JE2007439

[97] Javitt, J.C., Aiello, L.P., Bassi, L.J., et al. (1991) Detecting and Treating Retinopathy in Patients with Type 1 Diabetes Mellitus: Savings Associated with Improved Implementation of Current Guidelines. Ophthalmology, 98, 1565-1574. http://dx.doi.org/10.1016/S0161-6420(91)32086-4

[98] Klein, R., Klein, B.E., Neider, M.W., et al. (1985) Diabetic Retinopathy as Detected Using Ophthalmoscopy, a Nonmydriatic Camera and a Standard Fundus Camera. Ophthalmology, 92, 485-491. http://dx.doi.org/10.1016/S0161-6420(85)34003-4

[99] Maberley, D., Walker, H., Koushik, A., et al. (2003) Screening for Diabetic Retinopathy in James Bay, Ontario: A Cost-Effectiveness Analysis. Canadian Medical Association Journal, 168, 160-164.

[100] Heaven, C.J., Cansfield, J. and Shaw, K.M. (1993) The Quality of Photographs Produced by the Non-Mydriatic Fundus Camera in a Screening Programme for Diabetic Retinopathy: A 1 Year Prospective Study. Eye, 7, 787-790. http://dx.doi.org/10.1038/eye.1993.185

[101] Ahmed, J.T.P., Ward, S.E., Bursell, L.M., et al. (2006) The Sensitivity and Specificity of Nonmydriatic Digital Stereoscopic Retinal Imaging in Detecting Diabetic Retinopathy. Diabetes Care, 29, 2205-2209. http://dx.doi.org/10.2337/dc06-0295

[102] Hutchinson, A., Mclntosh, A., Peters, J., et al. (2000) Effectiveness of Screening and Monitoring Tests for Diabetic Retinopathy-A Systematic Review. Diabetic Medicine, 17, 495-506. http://dx.doi.org/10.1046/j.1464-5491.2000.00250.x

[103] Vijan, S., Hofer, T.P. and Hayward, R.A. (2000) Cost-Utility Analysis of Screening Intervals for Diabetic Retinopathy 
in Patients with Type 2 Diabetes Mellitus. The Journal of the American Medical Association, 283, 889-896. http://dx.doi.org/10.1001/jama.283.7.889

[104] Javitt, J.C. and Aiello, L.P. (1996) Cost-Effectiveness of Detecting and Treating Diabetic Retinopathy. Annals of Internal Medicine, 124, 164-169. http://dx.doi.org/10.7326/0003-4819-124-1_Part_2-199601011-00017

[105] Polak, B.C., Crijns, H., Casparie, A.F., et al. (2003) Cost-Effectiveness of Glycemic Control and Ophthalmological Care in Diabetic Retinopathy. Health Policy, 64, 89-97. http://dx.doi.org/10.1016/S0168-8510(02)00143-4

[106] Matz, H., Falk, M., Gottinger, W., et al. (1996) Cost-Benefit Analysis of Diabetic Eye Disease. Ophthalmologica, 210, 348-353. http://dx.doi.org/10.1159/000310742

[107] Peng, C.C., Chou, P., Tung, T.H., et al. (2009) Cost-Benefit Analysis of Screening for Diabetic Retinopathy among Chinese Type 2 Diabetes: Decision from Different Perspectives of a Population-Based Study in Kinmen, Taiwan. Health, 1, 63-72. http://dx.doi.org/10.4236/health.2009.14050

[108] The Diabetic Retinopathy Vitrectomy Study Research Group (1985) Early Vitrectomy for Severe Vitreous Hemorrhage in Diabetic Retinopathy. Two-Year Results of a Randomized Trial. DRVS Report No. 2. Archives of Ophthalmology, 103, 1644-1652. http://dx.doi.org/10.1001/archopht.1985.01050110038020

[109] The DCCT Research Group (1986) The Diabetes Control and Complications Trial (DCCT): Design and Methodologic Considerations for the Feasibility Phase. Diabetes, 35, 530-545. http://dx.doi.org/10.2337/diab.35.5.530

[110] DCCT (1995) The Effect of Intensive Diabetes Treatment on the Progression of Diabetic Retinopathy in InsulinDependent-Diabetes-Mellitus. Archives of Ophthalmology, 113, 36-51. http://dx.doi.org/10.1001/archopht.1995.01100010038019

[111] Stenkula, S. (1984) Photocoagulation in Diabetic Retinopathy. A Multicentre Study in Sweden. Acta Ophthalmologica, 162, $1-100$.

[112] The Diabetic Retinopathy Study Research Group (1981) Photocoagulation Treatment of Proliferative Diabetic Retinopathy. Clinical Application of Diabetic Retinopathy Study (DRS) Findings, DRS Report Number 8. Ophthalmology, 88, 583-600. 